\title{
The Fate of Beta-Cells in Type 2 Diabetes and the Possible Role of Pharmacological Interventions
}

\author{
Baptist Gallwitz \\ Medizinische Klinik IV, Universitätsklinikum Tübingen, Otfried-Müller-Str. 10, 72076 Tübingen, Germany, \\ e-mail:baptist.gallwitz@med.uni-tuebingen.de.
}

\begin{abstract}
This article gives an overview of two recent trials investigating rosiglitazone, a thiazolidinedione, in its potential to prevent type 2 diabetes (T2D) and in its effectiveness in monotherapy. Thiazolidinediones are among the most important developments of recent years for combating T2D and therefore worth to revisit. The possible influence of thiazolidines in improving beta-cell function is discussed as well as the
\end{abstract}

\section{Introduction}

$\mathcal{T}$ he recent focus on beta-cell function in type 2 C) diabetes (T2D) has gained renewed interest. In the pathophysiology of T2D, insulin resistance and a growing defect in insulin secretion are important characteristics [1-3]. The United Kingdom Prospective Diabetes Study (UKPDS) revealed that at the time of diagnosis $40-50 \%$ of beta-cell function is already lost with a further decrease in beta-cell function as the disease progresses [4]. None of the oral antidiabetic agents used in the UKPDS were capable of ameliorating the loss of beta-cell function. The decline in betacell function is seen as a cause for the necessity to intensify the therapy in T2D [5]. The attainment and maintenance of near-normal glycemia is very important since it reduces the risk of long-term complications of T2D [6-8].

Thiazolidinediones are oral antidiabetic agents introduced in the late 1990s which are known to reduce insulin resistance by sensitizing muscle, liver, and adi- potential effects on insulin resistance and obesity. Novel, incretin-based therapies (GLP-1 analogues and DPP-4 inhibitors) and their effects on beta-cell function and beta-cell mass are also summarized and critically evaluated.

Keywords: type 2 diabetes - thizolidinediones $\cdot$ rosiglitazone · DPP-4 inhibitors · incretin mimetics • beta-cell function $\cdot$ beta-cell mass

pose tissue to insulin by activating the PPAR $\gamma$ receptor [9]. Several clinical studies in subjects with prediabetes (i.e. impaired glucose tolerance, IGT, impaired fasting glucose, IFG, and previous gestational diabetes, pGDM) and also with T2D suggest that thiazolidinediones not only ameliorate insulin resistance, but also preserve beta-cell function [10-13]. This class of substances has therefore been considered to be beneficial for the treatment of T2D. In a large prospective study, the thiazolidinedione pioglitazone improved glycemic control and reduced cardiovascular complications that were defined as secondary endpoints [14].

\section{Rosiglitazone in diabetes prevention}

Two important large trials with rosiglitazone that were recently completed, have obtained important data in evaluating the clinical effectiveness of thiazolidinediones and their influence on beta-cell function, the Diabetes Reduction Assessment with Ramipril and Rosiglitazone Medication (DREAM) study and the A 


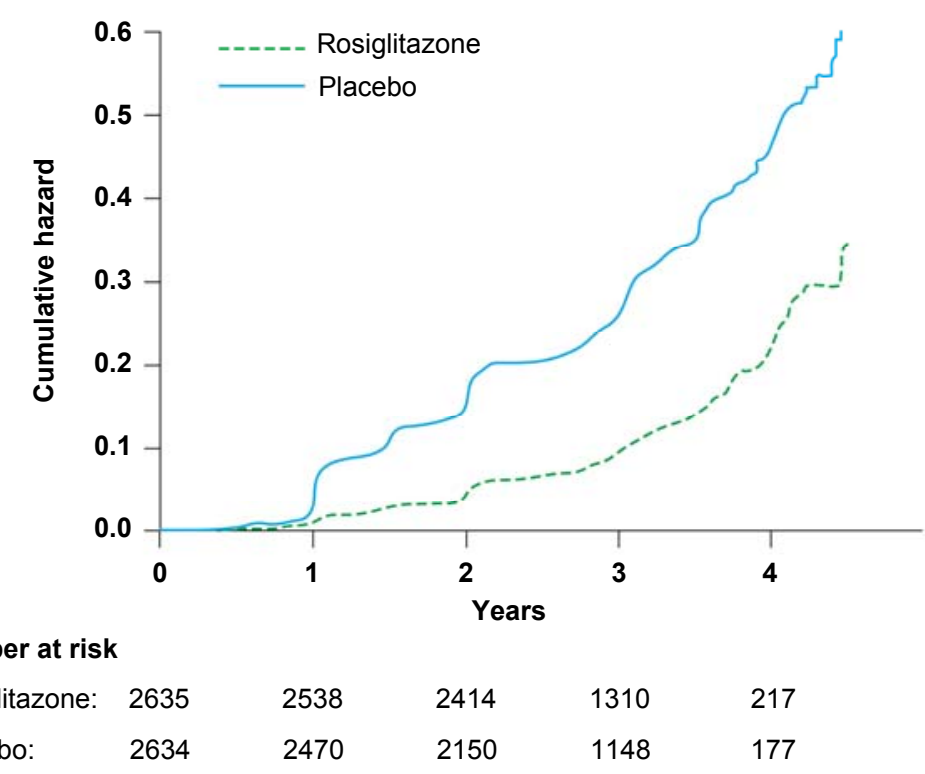

Figure 1. Time to occurrence of the primary outcome, the conversion to T2D, in the DREAM study. Results are reproduced based on [12].

Diabetes Outcome Progression Trial (ADOPT). The DREAM trial was designed to investigate the potency of rosiglitazone or ramipril to prevent or delay T2D in a prediabetic cohort of 5269 subjects with IGT or IFG without previous cardiovascular disease over a period of three years [12]. The study had a double-blind, randomized "2-by-2 factorial design". Subjects received ramipril in a daily dose of up to $15 \mathrm{mg} / \mathrm{d}$ or a placebo and rosiglitazone in a daily dose up to $8 \mathrm{mg} / \mathrm{d}$ or a placebo. The composite primary endpoint consisted of a conversion to T2D or death. A secondary endpoint was defined as regression from prediabetes (IFG or IGT) to normoglycemia.

Ramipril did not change the incidence of the primary endpoint in the "intention to treat" analysis $(18,1 \%$ with ramipril vs. $19,5 \%$ with placebo; hazard ratio 0.91 for ramipril, $95 \%$ confidence interval [CI] $0.81-1.03 ; \mathrm{p}=0.15)$. More patients in the ramipril group reached the secondary endpoint normoglycemia (hazard ratio 1.16, 95\% CI 1.07-1.27; $\mathrm{p}=0.001$ ). The fasting glucose was identical in both groups at the end of the study, the 2-hour glucose after an oral glucose tolerance test (OGTT) was lower in the ramipril group $(135.1 \mathrm{mg} / \mathrm{dl}$ vs. $140.5 \mathrm{mg} / \mathrm{dl}, \mathrm{p}=0.01)$ [15].

Rosiglitazone led to a $14.4 \%$ absolute risk reduction of the primary endpoint (hazard ratio 0.40, 95\% CI $0.35-0.46, \mathrm{p}<0.0001)$ corresponding to a number needed to treat (NNT) of 7 . The rosiglitazone group also showed better results concerning the secondary endpoint $(50.5 \%$ rosiglitazone vs. $30.3 \%$ placebo, hazard ratio $1.71,95 \%$ CI 1.57 1.87; $\mathrm{p}<0,0001)$. Congestive heart failure was more common in the rosiglitazone group (14 vs. 2 patients) and was not influenced by ramipril. Body weight increased significantly in the rosiglitazone group [12]. In summary, rosiglitazone reduced the diabetes incidence in subjects with IFG and IGT in the DREAM study, whereas ramipril had no effect (Figure 1). In a recent, still unpublished report, the results of the 3 months washout phase of the DREAM trial were reported at the International Diabetes Federation (IDF) conference. During the washout phase, the diabetes incidence increased in the rosiglitazone group, indicating that rosiglitazone does not promote a sustained effect to improve beta-cells function or beta-cell mass.

In diabetes prevention, a lifestyle intervention with the aim to increase physical activity and to change dietary habits with a reduction in the total caloric intake and reduction of saturated fatty acids is also highly effective. The Finnish Diabetes Prevention Study (DPS) showed that such a lifestyle intervention effectively reduced the relative risk of a progression from IGT to T2D by $58 \%$ in 4 years [16]. Additionally, a significant weight loss was observed in the subjects that received intensive multiprofessional counseling to achieve the goals of the lifestyle intervention. In subjects that reached all the predefined intervention goals, no progression to diabetes was observed. Similar results were observed in the Diabetes Prevention Program (DPP) $[17,18]$. In this study, an additional comparison was made between a lifestyle intervention and a pharmacological intervention with metformin. Metformin was less effective than the lifestyle intervention regarding the conversion to diabetes and concerning weight loss [18]. In an Indian-Asian population, a lifestyle intervention was also more effective than an intervention with metformin, the combination of lifestyle intervention and pharmacological intervention had no additional benefit in this group [19]. Despite the risk reduction for progression to diabetes with rosiglitazone observed in the DREAM trial, an intervention with rosiglitazone seems unfeasible for subjects with impaired glucose regulation and low absolute cardiovascular risk. First of all, the rosiglitazone dose chosen in the DREAM trial was comparatively 
high, at $8 \mathrm{mg} / \mathrm{d}$. The greater benefits in higher risk individuals would have to be balanced against the likely increased risk of heart failure [14, 20]. Lifestyle interventions for diabetes prevention have been shown to be cost effective and their effect is sustained for a long time span, in contrast to the negative results of the wash-out phase in the DREAM trial [21]. Therefore, such non-pharmacological interventions should remain the mainstay for the prevention of T2D [22].

\section{Rosiglitazone and the failure of oral mono- therapy}

The ADOPT study was a clinical trial designed to evaluate the durability of glycemic control in patients with T2D receiving monotherapy with either rosiglitazone, metformin or the sulfonylurea glyburide (glibenclamide). All patients were treatment-naïve concerning diabetes therapy and had a duration of diabetes of less
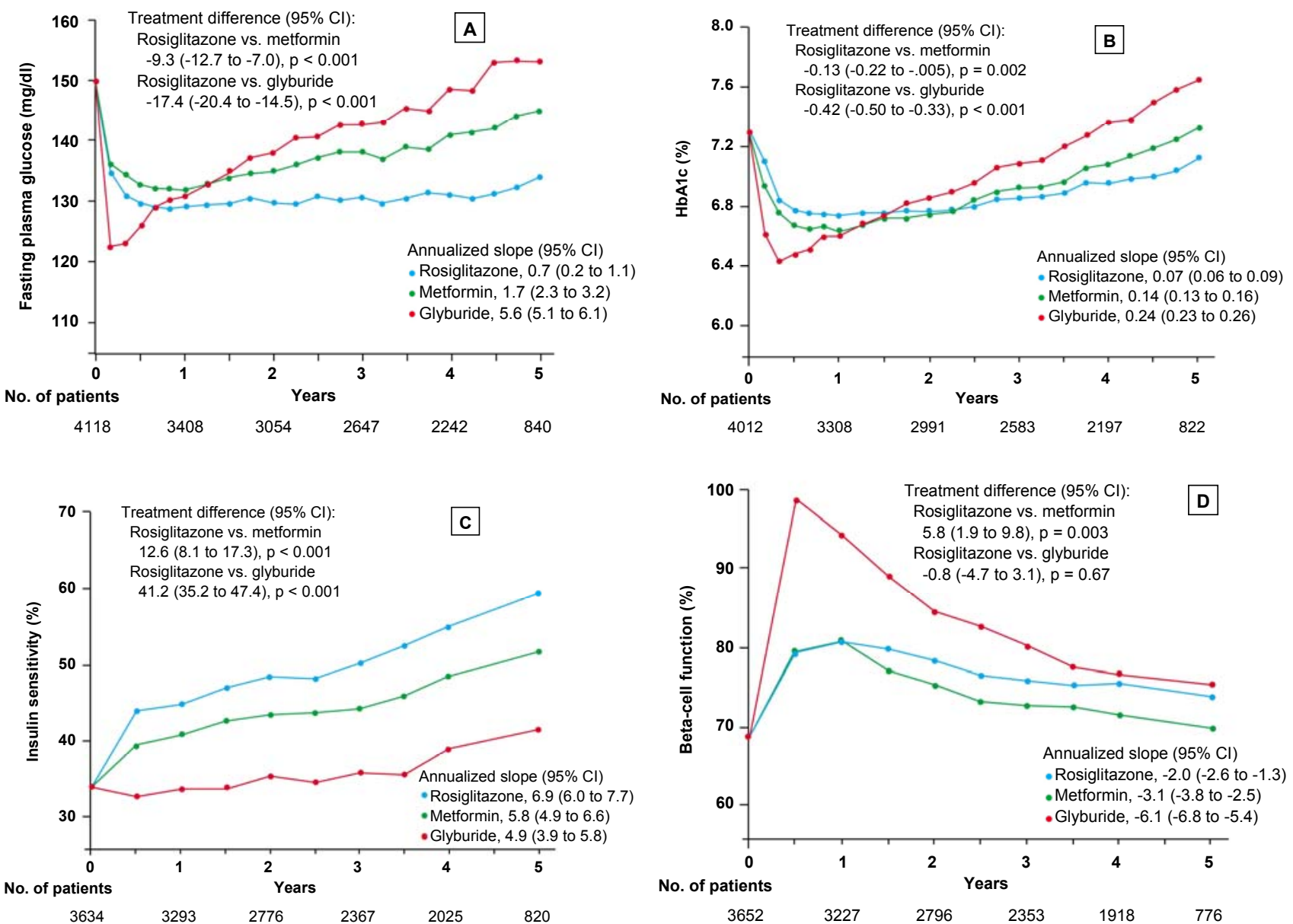

Figure 2. Fasting plasma glucose (A), glycated hemoglobin (B), insulin sensitivity (C) and beta-cell function (D) in the ADOPT trial [25]. The total number of patients included for each measurement at annual time points is indicated below each graph. In all panels, data are presented as means \pm SEM, with the treatment difference at 4 years and the annualized rate of change (slope) from 0.5 to 5 years. Insulin sensitivity and beta-cell function were determined by homeostasis model assessment (HOMA 2) and are expressed as a percentage of the value in a normal reference population. The treatment difference is expressed as the relative percentage difference between the rosiglitazone group and each comparison group at 4 years; the slopes are the annual percent change. Asterisks denote significant differences between the rosiglitazone group and the other treatment groups with the Hochberg adjustment. Results are reproduced based on [25]. 
than three years when entering the trial. The primary outcome was the time to monotherapy failure on the basis of fasting plasma glucose levels of $>180 \mathrm{mg} / \mathrm{dl}$ after an overnight fast. The trial enabled the direct comparison of the metabolic effects of these three commonly used glucose-lowering agents over a median period of 4 years in 4360 patients. Secondary endpoints were the levels of fasting plasma glucose and glycated hemoglobin, insulin sensitivity, and beta-cell function $[23,24]$.

In this prospective, double-blind, randomized multicenter study, the cumulative incidence of monotherapy failure at 5 years was $15 \%$ with rosiglitazone, $21 \%$ with metformin, and 34\% with glyburide. The corresponding relative risk reduction for rosiglitazone was $32 \%$, as compared with metformin, and $63 \%$, as compared with glyburide ( $\mathrm{p}<0.001$ for both comparisons). At the 4-year evaluation, $40 \%$ of the 1456 patients in the rosiglitazone group had a glycated hemoglobin level of less than $7 \%$, as compared with $36 \%$ of the 1454 patients in the metformin group $(p=0.03)$ and $26 \%$ of the 1441 patients in the glyburide group ( $\mathrm{p}<$ 0.001). The maximal treatment effect on glycated hemoglobin was achieved at 12 months for patients in the rosiglitazone and metformin groups and at 4 months for those in the glyburide group. The difference in the durability of the treatment effect was greater between rosiglitazone and glyburide than between rosiglitazone and metformin. After the 4 year observational period, the difference in the mean HbA1c between the metformin group and the rosiglitazone group was negligible with only a $0.13 \%$ difference in favor of rosiglitazone. Beta-cell function, as determined by homeostasis model assessment (HOMA), showed a higher increase in the glyburide group (mean ratio of the 6 -month value to the baseline value, $1.45 ; 95 \% \mathrm{CI}, 1.42$ to 1.48$)$ than in either the rosiglitazone group $(1.17 ; 95 \% \mathrm{CI}, 1.15$ to 1.19$)$ or the metformin group $(1.16 ; 95 \%$ CI, 1.14 to 1.19$)$. Thereafter, levels of beta-cell function determined by HOMA declined in all three groups (Figure 2). The annual rate of decline after 6 months was greatest in the glyburide group (6.1\%), followed by the metformin group $(3.1 \%)$ and the rosiglitazone group $(2.0 \%)(\mathrm{p}<$ 0.001 for the comparison rosiglitazone vs. glyburide and $\mathrm{p}=0.02$ for the comparison rosiglitazone vs. metformin). The therapy with the sulfonylurea glyburide was associated with a lower risk of cardiovascular events including congestive heart failure than the therapy with the thiazolidinedione rosiglitazone $(p<0.05)$. The cardiovascular risk associated with metformin was similar to that with rosiglitazone. Rosiglitazone treat- ment was associated with more weight gain $(4.8 \mathrm{~kg}$ weight gain; $95 \% \mathrm{CI}, 4.3$ to 5.3 ) and edema than either metformin (-2.9 kg weight loss; 95\% CI, -3.4 to -2.3$)$ or glyburide (1.6 kg weight gain; 95\% CI, 1.0 to 2.2 ) but with fewer gastrointestinal events than metformin and with less hypoglycemia than glyburide $(\mathrm{p}<0.001$ for all comparisons) [25].

The authors of the study conclude that an initial treatment of T2D in therapy-naive patients with rosiglitazone slowed the progression to monotherapy failure more effectively than did either metformin or glyburide. Although rosiglitazone was more effective overall than metformin in this study, heterogeneity analyses showed no subgroup differences apart from a greater effect in older patients and those with a larger waist circumference [25]. It is not known, whether the differences between the different pharmacological agents investigated in the ADOPT-trial have any effect on disease progression or on vascular complications.

In the new joint consensus statement on the management of hyperglycemia in T2D released by the American Diabetes Association (ADA) and the European Association for the Study of Diabetes (EASD) [26], the algorithm for the initiation of treatment of T2D has defined a lifestyle intervention and met-

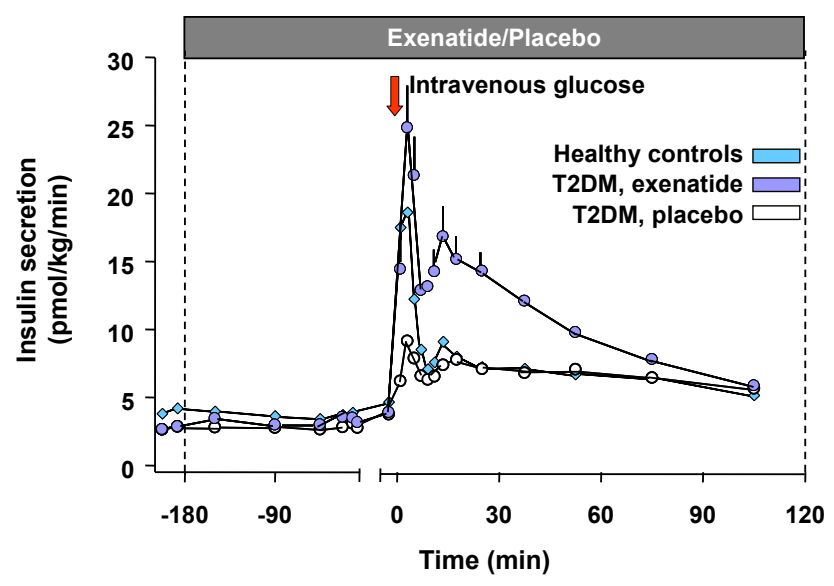

Figure 3. Insulin secretion rates in 13 subjects with T2D given an i.v. infusion of exenatide or saline and 12 healthy volunteers given an i.v. infusion of saline. Repeatedmeasures ANOVA indicated significant differences in insulin secretion as measured by AUC analysis of the first (0$10 \mathrm{~min}$ ) and second-phase (10-120 $\mathrm{min}$ ) insulin release between subjects with T2D treated with exenatide and saline. Exenatide-treated T2D subjects also had a significantly increased second-phase insulin release, compared with healthy volunteers. Data represent mean \pm SEM. Results are reproduced based on [35]. 
formin therapy as the first step after the diagnosis of diabetes. Metformin has been chosen on the basis of the favorable data of the UKPDS and due to the long experience and low costs associated with this drug [7]. The UKPDS also demonstrated a beneficial effect of metformin therapy on CVD outcomes [7], which needs to be confirmed. Metformin therapy is not associated with weight gain, but with weight neutrality or even modest weight loss. Thiazolidinediones are included in the treatment algorithm as a second step in conjunction with metformin, if one of the therapeutic aims is to avoid hypoglycemia [26]. This decision is mainly based on limited data concerning the glucose lowering effect and on long term outcome data with thiazolidinediones in monotherapy. An additional disadvantage of the thiazolidinediones is the weight gain caused by an increase in subcutaneous adiposity and fluid retention. As mentioned above, this therapy is also associated with an increase in congestive heart failure [27]. In the second step of treatment intensification, the alternatives to adding a thiazolidinedione to metformin are adding a sulfonylurea or basal insulin. The latter is considered to be the most effective option. According to the consensus guideline, monotherapy with rosiglitazone is not feasible as the first therapeutic step in T2D therapy.

\section{Thiazolidinediones and beta-cell function}

The results with a high dose of rosiglitazone on diabetes prevention in the DREAM study are not unexpected, since another thiazolidinedione, troglitazone, reduced the incidence of T2D in the TRIPOD and the DPP (Diabetes Prevention Programme) study. Troglitazone was even more effective than metformin or acarbose in the diabetes prevention trials $[10,11,28]$. So far, there are no mechanistic studies in prediabetes demonstrating a thiazolidinedione-induced direct improvement of beta-cell function. Animal experiments show some evidence that thiazolidinediones may preserve beta-cell function [29]. These experiments unfortunately do not clarify whether this is a direct effect by lowering the concentrations of beta-cell toxic free fatty acids or tumor necrosis factor alpha (TNF- $\alpha$ ) or whether this is just an effect explained by normalization of glucose and ameliorating glucose toxicity. The negative results on the preservation of beta-cell function in the wash-out phase of the DREAM study and the observation in the ADOPT trial concerning the gradual decline of beta-cell function over time in the rosiglitazone group leave some doubt about the hypothesis that thiazolidinediones have a specifically beneficial effect on beta-cell function. The hope that thiazolidinediones may affect the underlying pathophysiology of T2D by protecting beta-cell function and may alter the course of the disease is only weakly supported by ADOPT. The initial improvement in insulin secretion at 1 year was not sustained, and the difference in insulin secretion between rosiglitazone and metformin over time, albeit significant, was small in real terms. Improved insulin sensitivity appears to be the most durable effect of rosiglitazone [30]. More studies are warranted to elucidate the potential mechanisms by which thiazolidinediones affect beta-cell function. Thiazolidinediones, especially rosiglitazone, also improve fatty liver (steatosis hepatis) in T2D and could therefore influence beta-cell function indirectly by changing the pattern of secretion of hepatic factors acting on the beta-cell [31].

\section{Incretin based therapies and beta-cell func- tion}

Concerning the influence of positive pharmacologic actions on beta-cell function and beta-cell mass, increasing study data are being collected from incretinbased therapies for T2D. These treatments use either pharmacologically high concentrations of the incretin hormone glucagon-like peptide-1 (GLP-1) in the form of degradation resistant GLP-1 analogs, or elevate endogenous GLP-1 concentrations by inhibiting the degradation of GLP-1 through the enzyme dipeptidyl peptidase IV (DPP-4) [32]. While GLP-1 analogs are peptides that need to be injected subcutaneously for therapy, DPP-4 inhibitors are orally active.

Exenatide (Byetta $\left.{ }^{\circledR}\right)$ is the first incretin mimetic peptide that was approved for T2D therapy in patients not controlled with a treatment of either metformin, a sulfonylurea or a combination of both [33]. In animal studies, exenatide improved beta-cell function and increased beta-cell mass. Exenatide causes an increase of beta-cell mass through the stimulation of islet cell neogenesis from precursor cells on the one hand, and through the inhibition of apoptosis of beta-cells on the other [34]. In man, there are indirect data showing an improvement in various surrogate parameters for betacell function, along this line, the first phase of insulin secretion is restored by exenatide treatment [35] (Figure 3). In clinical studies available on exenatide so far, this treatment led to a sustained $\mathrm{HbA1c}$ reduction of $1.1 \%$ in a study period of 2 years and a continuous and significant body weight reduction of $4.7 \mathrm{~kg}$ on average. The HbA1c reduction was independent from the weight loss [33, 36]. Furthermore, exenatide was able 
to restore the first phase of insulin secretion in T2D patients [35].

So far, there are no clinical endpoint studies with exenatide proving a halt in, or substantial influence on disease progression of T2D with exenatide therapy [33]. Liraglutide, a GLP-1 analogue still in phase III clinical studies, also showed positive effects on betacell function and mass in animal models [37]. In clinical studies, liraglutide lowered $\mathrm{HbA1c}$ and fasting plasma glucose dose dependently (HbA1c reduction $0.75 \%$ with $0,75 \mathrm{mg} / \mathrm{d}$ liraglutide in a 12 week study) and promoted weight loss $[37,38]$. In a step-wise hyperglycemic clamp study, liraglutide improved beta-cell responsiveness in T2D patients [39].

Currently, there are two DPP-4 inhibitors: sitagliptin and vildagliptin, which are far advanced in development. Sitagliptin has just been approved for T2D therapy. The sitagliptin analogue des-fluoro sitagliptin improved glycemic parameters in a diabetic mouse model and normalized islet cell architecture and insulin content [40] (Figure 4). Further mechanistic studies are needed to show whether this is a direct effect of the DPP-4 inhibitor on beta-cells or whether the improvement is mediated by the normalization of glucose. Vildagliptin also improved beta-cell function in a mouse model [41] as well as postprandial beta-cell function parameters in man in a one-year clinical study [42].

In a 24 week clinical study, sitagliptin in montherapy lowered HbA1c up to maximally $0.94 \%$ dependent on the baseline $\mathrm{HbA1c}$ and the dose of sitaglitptin. In a meal tolerance test, sitagliptin 100 and $200 \mathrm{mg}$ significantly decreased 2-h postprandial glucose (PPG) (placebo-subtracted PPG -46.7 $\mathrm{mg} / \mathrm{dl}$ and $-54.1 \mathrm{mg} / \mathrm{dl}$, respectively). Results for the above mentioned key efficacy parameters were not significantly different between sitagliptin doses. The HOMA of beta-cell function and proinsulin-to-insulin ratio improved with sitagliptin. The incidence of hypoglycemia was similar, and overall gastrointestinal adverse experiences were slightly higher with sitagliptin. No meaningful body weight changes from baseline were observed with sitagliptin $100(-0.2 \mathrm{~kg})$ or $200 \mathrm{mg}(-0.1 \mathrm{~kg})$ [43].

In a study comparing the effectiveness of vildagliptin with rosiglitazone directly over 24 weeks, HbA1c was reduced to a similar extent. At the end of the study, vildagliptin was as effective as rosiglitazone, improving HbA1c by -1.1 ( $\mathrm{p}<0.001$ ) and -1.3 ( $\mathrm{p}<$ $0.001)$, respectively, meeting the statistical criterion for

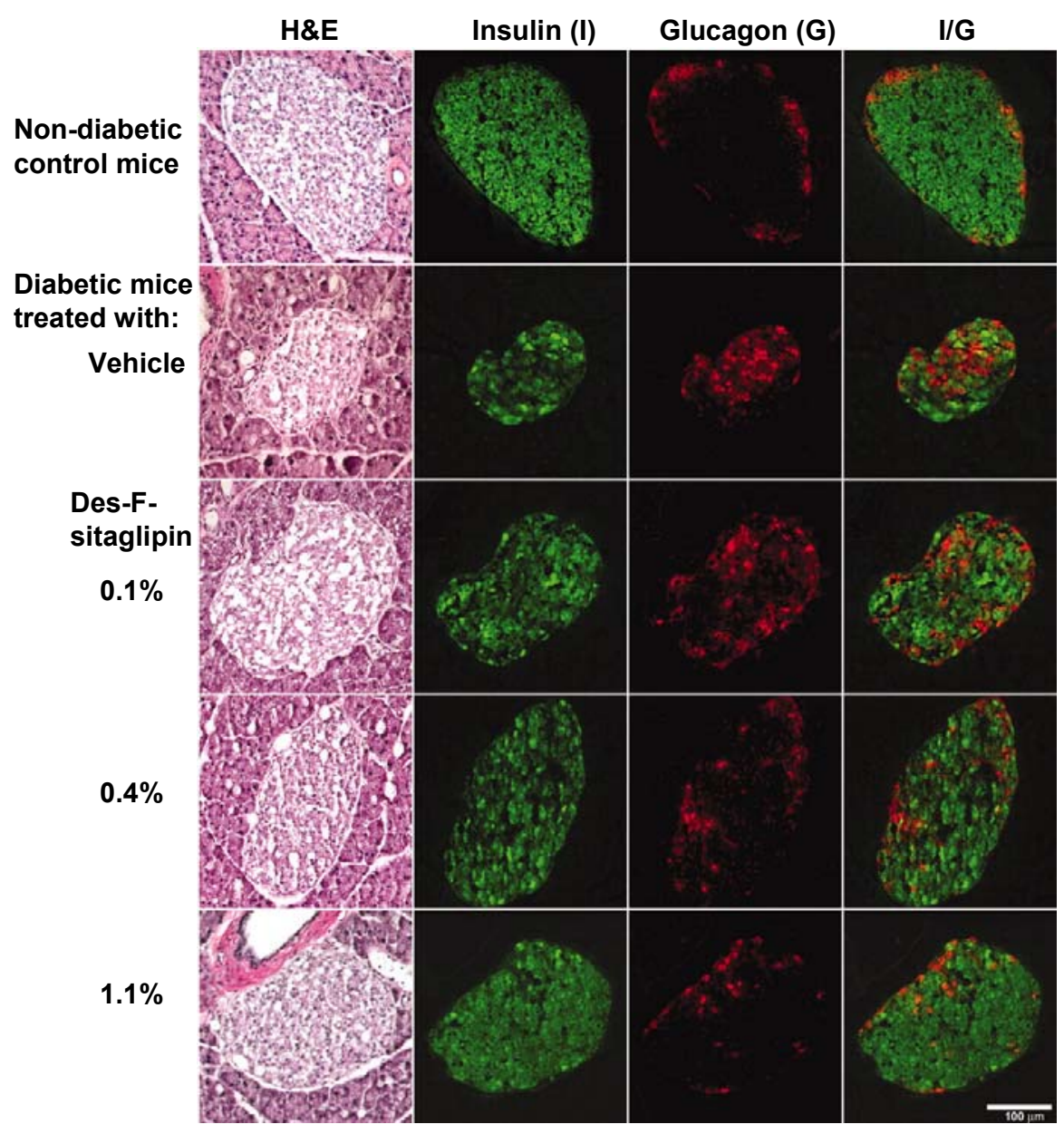

Figure 4. Immunohistochemical analysis of pancreatic sections of HFD/STZdiabetic mice treated with vehicle or des-fluoro-sitagliptin. Mice were treated with des-F-sitagliptin at indicated dosages for 11 weeks. Whole pancreas from each mouse was cryopreserved, and consecutive sections were stained with hematoxylin and eosin (H\&E), anti-insulin antibody (green), or anti-glucagon antibody (red). Shown are representative islets from each group with each staining, and the overlay of the insulin and glucagon staining (I/G). Reproduced based on [40]. 
non-inferiority (upper-limit 95\% CI for betweentreatment difference $\leq 0.4 \%$ ). The fasting plasma glucose decreased more with rosiglitazone than with vildagliptin. Body weight did not change in vildagliptintreated patients $(-0.3 \mathrm{~kg})$ but increased in rosiglitazonetreated patients $(+1.6 \mathrm{~kg}, \mathrm{p}<0.001$ vs. vildagliptin). Relative to rosiglitazone, vildagliptin significantly decreased triglycerides, total cholesterol, and LDL, nonHDL, and total-to-HDL cholesterol (-9 to $-16 \%$, all $\mathrm{p}$ $<0.01)$ but produced a smaller increase in HDL cholesterol ( +4 vs. $+9 \%, \mathrm{p}=0.003)$. The incidence of edema was greater with rosiglitazone $(4.1 \%)$ than vildagliptin $(2.1 \%)$ [44].

Like for the GLP-1 analogues, there are no endpoint studies with the novel substance class of the DPP-4 inhibitors yet. It is therefore not clear as to whether these substances will be able to change the disease progression of T2D in clinical practice.

\section{Conclusions}

The relative effectiveness and relative costs of antidiabetic medications, their exact profiles of adverse events, and their potential risks and benefits should be considered, to help inform the choice of pharmacotherapy for patients with T2D [45]. From the study data presented here, incretin-based therapies show an effectiveness on glycemic parameters that is comparable to established treatment forms for T2D. However, these therapies have the advantage of being either weight neutral (DPP-4 inhibitors) or even capable of promoting weight loss (incretin mimetics). Besides these effects on body weight, data from different studies (animal models, isolated islet cell models and in clinical studies) suggest a beneficial effect of incretins on beta-cell function independent of glucose lowering. Another advantage over thiazolidinediones is the pattern of side-effects, where incretin-based therapies do not show an increase in congestive heart failure. However, endpoint studies are needed to investigate the potential of incretin mimetics and DPP-4 inhibitors to influence the course of T2D and increasing beta-cell failure as well as studies showing other positive endpoints.

\section{References}

1. Polonsky KS, Given BD, Hirsch LJ, Tillil H, Shapiro ET, Beebe C, Frank BH, Galloway JA, Van Cauter E. Abnormal patterns of insulin secretion in non-insulin-dependent diabetes mellitus. N Engl J Med 1988. 318:1231-1239.

2. Weir GC, Bonner-Weir S. Five stages of evolving beta-cell dysfunction during progression to diabetes. Diabetes 2004. 53(Suppl)3:S16-S21.

3. Scheen AJ. Diabetes mellitus in the elderly: insulin resistance and/or impaired insulin secretion? Diabetes Metab 2005. 31(Spec No)2:5S27-5S34.

4. Holman RR. Assessing the potential for alpha-glucosidase inhibitors in prediabetic states. Diabetes Res Clin Pract 1998. 40(Suppl):S21-S25.

5. U.K. Prospective Diabetes Study Group. U.K. prospective diabetes study 16. Overview of 6 years' therapy of type II diabetes: a progressive disease. UKPDS 16. Diabetes 1995. 44:1249-1258.

6. UK Prospective Diabetes Study Group. Intensive bloodglucose control with sulphonylureas or insulin compared with conventional treatment and risk of complications in patients with type 2 diabetes (UKPDS 33). Lancet 1998. 352(9131):837853.

7. UK Prospective Diabetes Study Group. Effect of intensive blood-glucose control with metformin on complications in overweight patients with type 2 diabetes (UKPDS 34). Lancet 1998. 352(9131):854-865.

8. Ohkubo Y, Kishikawa H, Araki E, Miyata T, Isami S, Motoyoshi S, Kojima Y, Furuyoshi N, Shichiri M. Intensive insulin therapy prevents the progression of diabetic microvascular complications in Japanese patients with noninsulin-dependent diabetes mellitus: a randomized prospective 6-year study. Diabetes Res Clin Pract 1995. 28:103-117.
9. Yki-Jarvinen H. Thiazolidinediones. N Engl J Med 2004. 351:1106-1118.

10. Buchanan TA, Xiang AH, Peters RK, Kjos SL, Marroquin A, Goico J, Ochoa C, Tan S, Berkowitz K, Hodis HN, Azen SP. Preservation of pancreatic beta-cell function and prevention of type 2 diabetes by pharmacological treatment of insulin resistance in high-risk hispanic women. Diabetes 2002. 51:2796-2803.

11. Knowler WC, Hamman RF, Edelstein SL, Barrett-Connor E, Ehrmann DA, Walker EA, Fowler SE, Nathan DM, Kahn SE. Prevention of type 2 diabetes with troglitazone in the Diabetes Prevention Program. Diabetes 2005. 54:1150-1156.

12. Gerstein HC, Yusuf S, Bosch J, Pogue J, Sheridan P, Dinccag N, Hanefeld M, Hoogwerf B, Laakso M, Mohan V, Shaw J, Zinman B, Holman RR. Effect of rosiglitazone on the frequency of diabetes in patients with impaired glucose tolerance or impaired fasting glucose: a randomised controlled trial. Lancet 2006. 368:1096-1105.

13. Ehrmann DA, Schneider DJ, Sobel BE, Cavaghan MK, Imperial J, Rosenfield RL, Polonsky KS. Troglitazone improves defects in insulin action, insulin secretion, ovarian steroidogenesis, and fibrinolysis in women with polycystic ovary syndrome. J Clin Endocrinol Metab 1997. 82:2108-2116.

14. Dormandy JA, Charbonnel B, Eckland DJ, Erdmann E, Massi-Benedetti M, Moules IK, Skene AM, Tan MH, Lefebvre PJ, Murray GD, et al. Secondary prevention of macrovascular events in patients with type 2 diabetes in the PROactive Study (PROspective pioglitAzone Clinical Trial In macroVascular Events): a randomised controlled trial. Lancet 2005. 366:1279-1289.

15. Bosch J, Yusuf S, Gerstein HC, Pogue J, Sheridan P, Dagenais G, Diaz R, Avezum A, Lanas F, Probstfield J, Fodor G, Holman RR. Effect of ramipril on the incidence of diabetes. N Engl J Med 2006. 355:1551-1562. 
16. Tuomilehto J, Lindstrom J, Eriksson JG, Valle TT, Hamalainen $\mathbf{H}$, Ilanne-Parikka P, KeinanenKiukaanniemi S, Laakso M, Louheranta A, Rastas M, Salminen V, Uusitupa M. Prevention of type 2 diabetes mellitus by changes in lifestyle among subjects with impaired glucose tolerance. N Engl J Med 2001. 344:1343-1350.

17. Diabetes Prevention Program Research Group. The Diabetes Prevention Program (DPP): description of lifestyle intervention. Diabetes Care 2002. 25:2165-2171.

18. Knowler WC, Barrett-Connor E, Fowler SE, Hamman RF, Lachin JM, Walker EA, Nathan DM. Reduction in the incidence of type 2 diabetes with lifestyle intervention or metformin. N Engl J Med 2002. 346:393-403.

19. Ramachandran A, Snehalatha C, Mary S, Mukesh B, Bhaskar AD, Vijay V. The Indian Diabetes Prevention Programme shows that lifestyle modification and metformin prevent type 2 diabetes in Asian Indian subjects with impaired glucose tolerance (IDPP-1). Diabetologia 2006. 49:289-297.

20. Levitan EB, Song Y, Ford ES, Liu S. Is nondiabetic hyperglycemia a risk factor for cardiovascular disease? A metaanalysis of prospective studies. Arch Intern Med 2004. 164:21472155.

21. Herman WH, Hoerger TJ, Brandle M, Hicks K, Sorensen S, Zhang P, Hamman RF, Ackermann RT, Engelgau MM, Ratner RE. The cost-effectiveness of lifestyle modification or metformin in preventing type 2 diabetes in adults with impaired glucose tolerance. Ann Intern Med 2005. 142:323-332.

22. Tuomilehto J, Wareham N. Glucose lowering and diabetes prevention: are they the same? Lancet 2006. 368:1218-1219.

23. Viberti G, Kahn SE, Greene DA, Herman WH, Zinman B, Holman RR, Haffner SM, Levy D, Lachin JM, Berry RA, Heise MA, Jones NP, Freed MI. A diabetes outcome progression trial (ADOPT): an international multicenter study of the comparative efficacy of rosiglitazone, glyburide, and metformin in recently diagnosed type 2 diabetes. Diabetes Care 2002. 25:1737-1743

24. Viberti G, Lachin J, Holman R, Zinman B, Haffner S, Kravitz B, Heise MA, Jones NP, O'Neill MC, Freed MI, Kahn SE, Herman WH. A Diabetes Outcome Progression Trial (ADOPT): baseline characteristics of Type 2 diabetic patients in North America and Europe. Diabet Med 2006. 23:1289-1294.

25. Kahn SE, Haffner SM, Heise MA, Herman WH, Holman RR, Jones NP, Kravitz BG, Lachin JM, O'Neill MC, Zinman B, Viberti G. Glycemic durability of rosiglitazone, metformin, or glyburide monotherapy. N Engl J Med 2006. 355:2427-2443.

26. Nathan DM, Buse JB, Davidson MB, Heine RJ, Holman RR, Sherwin R, Zinman B. Management of hyperglycaemia in type 2 diabetes: a consensus algorithm for the initiation and adjustment of therapy. A consensus statement from the American Diabetes Association and the European Association for the Study of Diabetes. Diabetologia 2006. 49:1711-1721.

27. Boden G, Zhang M. Recent findings concerning thiazolidinediones in the treatment of diabetes. Expert Opin Investig Drugs 2006. 15:243-250.

28. Chiasson JL, Josse RG, Gomis R, Hanefeld M, Karasik A, Laakso M. Acarbose for prevention of type 2 diabetes mellitus: the STOP-NIDDM randomised trial. Lancet 2002. 359:2072-2077.

29. Leiter LA. Beta-cell preservation: a potential role for thiazolidinediones to improve clinical care in Type 2 diabetes. Dia- bet Med 2005. 22:963-972.

30. Nathan DM. Thiazolidinediones for initial treatment of type 2 diabetes? N Engl J Med 2006. 355:2477-2480.

31. Stumvoll M. Control of glycaemia: from molecules to men. Minkowski Lecture 2003. Diabetologia 2004. 47:770-781.

32. Drucker DJ, Nauck MA. The incretin system: glucagon-like peptide-1 receptor agonists and dipeptidyl peptidase- 4 inhibitors in type 2 diabetes. Lancet 2006. 368:1696-1705.

33. Gallwitz B. Exenatide in type 2 diabetes: treatment effects in clinical studies and animal study data. Int J Clin Pract 2006. 60:1654-1661.

34. Brubaker PL, Drucker DJ. Minireview: Glucagon-like peptides regulate cell proliferation and apoptosis in the pancreas, gut, and central nervous system. Endocrinology 2004. 145:26532659.

35. Fehse F, Trautmann M, Holst JJ, Halseth AE, Nanayakkara N, Nielsen LL, Fineman MS, Kim DD, Nauck MA. Exenatide augments first- and second-phase insulin secretion in response to intravenous glucose in subjects with type 2 diabetes. J Clin Endocrinol Metab 2005. 90:59915997.

36. Riddle MC, Henry RR, Poon TH, Zhang B, Mac SM, Holcombe JH, Kim DD, Maggs DG. Exenatide elicits sustained glycaemic control and progressive reduction of body weight in patients with type 2 diabetes inadequately controlled by sulphonylureas with or without metformin. Diabetes Metab Res Rev 2006. 22:483-491.

37. Vilsboll T. Liraglutide: a once-daily GLP-1 analogue for the treatment of Type 2 diabetes mellitus. Expert Opin Investig Drugs 2007. 16:231-237.

38. Madsbad S, Schmitz O, Ranstam J, Jakobsen G, Matthews DR. Improved glycemic control with no weight increase in patients with type 2 diabetes after once-daily treatment with the long-acting glucagon-like peptide 1 analog liraglutide (NN2211): a 12-week, double-blind, randomized, controlled trial. Diabetes Care 2004. 27:1335-1342.

39. Chang AM, Jakobsen G, Sturis J, Smith MJ, Bloem CJ, An B, Galecki A, Halter JB. The GLP-1 derivative NN2211 restores beta-cell sensitivity to glucose in type 2 diabetic patients after a single dose. Diabetes 2003. 52:1786-1791.

40. Mu J, Woods J, Zhou YP, Roy RS, Li Z, Zycband E, Feng Y, Zhu L, Li C, Howard AD, Moller DE, Thornberry NA, Zhang BB. Chronic inhibition of dipeptidyl peptidase-4 with a sitagliptin analog preserves pancreatic beta-cell mass and function in a rodent model of type 2 diabetes. Diabetes 2006. 55:1695-1704.

41. Ahren B, Sorhede Winzell M, Burkey B, Hughes TE. Beta-cell expression of a dominant-negative HNF-1alpha compromises the ability of inhibition of dipeptidyl peptidase- 4 to elicit a long-term augmentation of insulin secretion in mice. Eur J Pharmacol 2005. 521:164-168.

42. Ahren B, Pacini G, Foley JE, Schweizer A. Improved mealrelated beta-cell function and insulin sensitivity by the dipeptidyl peptidase-IV inhibitor vildagliptin in metformin-treated patients with type 2 diabetes over 1 year. Diabetes Care 2005. 28:1936-1940.

43. Aschner P, Kipnes MS, Lunceford JK, Sanchez M, Mickel C, Williams-Herman DE. Effect of the dipeptidyl peptidase4 inhibitor sitagliptin as monotherapy on glycemic control in patients with type 2 diabetes. Diabetes Care 2006. 29:2632-2637.

44. Rosenstock J, Baron MA, Dejager S, Mills D, Schweizer A. Comparison of vildagliptin and rosiglitazone monotherapy 
in patients with type 2 diabetes: a 24-week, double-blind, randomized trial. Diabetes Care 2007. 30:217-223.
45. Nathan DM. Finding new treatments for diabetes--how many, how fast... how good? N Engl J Med 2007. 356(5):437-440. 